\title{
Espectáculo, normalización y representaciones otras. Las personas transgénero en la prensa y el cine de Colombia y Venezuela
}

\section{María Toscano Alonso}

Universidad de Sevilla maria.toscano.alonso@gmail.com https://orcid.org/0000-0002-7263-3400

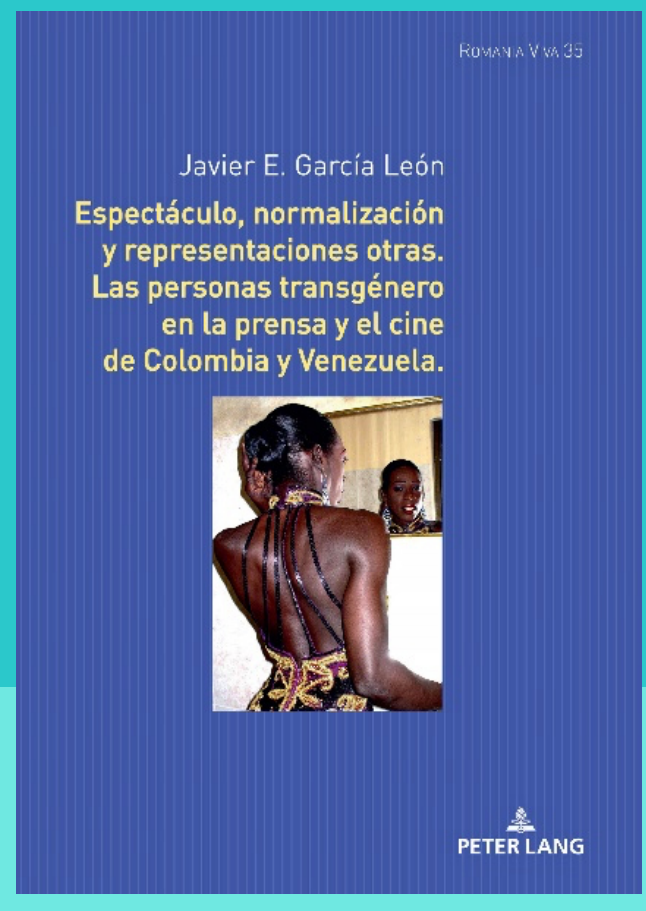

Javier E. García León Peter Lang

2021

194 páginas 
En un momento en el que los estudios de género y la teoría queer están comenzando a posicionarse en el centro de los discursos sociales, políticos y culturales con mayor ahínco, relevancia y contundencia, también la investigación y el ámbito académico están proliferando en el abordaje de estas cuestiones. Cada vez más textos tienen como foco el estudio LQTBIQ+ a lo largo de todo el mundo.

En esta ocasión, García León centra sus esfuerzos en el análisis de la prensa y el cine de dos países de América Latina: Colombia y Venezuela. Concretamente, estudia la representación que se hace en ambos medios de las personas trans. El autor comienza el libro introduciendo diversos conceptos e ideas relativas a la perspectiva queer, una introducción que bien puede asemejarse, aunque de manera más sintética, al desglose terminológico que realiza Stryker en Historia de lo trans (2017). En este comienzo del texto, se asientan las bases necesarias para que los y las lectoras comprendan los matices y las implicaciones que tienen los términos empleados a lo largo de todo el libro para hablar de la identidad trans en sus diversas formas.

Espectáculo, normalización y representaciones otras. Las personas transgénero en la prensa y el cine de Colombia y Venezuela se divide en cuatro capítulos, sin incluir la introducción y las conclusiones. En el primer capítulo, el autor se centra en la prensa colombiana, concretamente en los periódicos: El Tiempo y El Espectador. Entre otros aspectos, destaca la vinculación entre el sistema político y socioeconómico y las representaciones de la identidad. Además, García León divide en tres categorías las representaciones que hace la prensa de las personas trans, siendo estas o bien monstruosas, o bien engañadoras o, por último, patéticas. Desarrollando ampliamente los resultados que dan lugar a esta categorización.

Posteriormente, encontramos un acercamiento a la industria cinematográfica colombiana donde se hallan representaciones que difieren con las ideas perpetuadas por la prensa, "a grandes rasgos, el cine trans colombiano debe ser entendido como una producción que permite comprender las interseccionalidades que constituyen a la persona trans a la par que denunciar formas de opresión" (p.94). El autor realiza un análisis de la obra de Ana Cristina Monroy Este pueblo necesita un muerto (2007) donde se atiende a la perspectiva decolonial del film. Otros aspectos de esta obra también son estudiados y puestos en discusión, por ejemplo, la relevancia de la muerte como elemento liberador, así como medio para la expresión de los sentimientos. Temas como la identidad cultural, el blanqueamiento que se ha tratado de hacer de la comunidad afrocolombiana y del colectivo trans, entre otros, aparecen representados en el filme y son analizados a lo largo del capítulo.

El tercer gran apartado de este libro se detiene en el estudio de la prensa venezolana. Se destacan las diferencias contextuales y circunstanciales que han envuelto a la lucha por los derechos LGTBIQ+ en Venezuela y Colombia. Por ello, del mismo modo, se encuentran diferencias en las publicaciones de los diarios nacionales sobre esta cuestión, aunque también similitudes. En esta ocasión, la situación política difiere, siendo Venezuela un país que se autoproclama "respetuoso de la diversidad sexual" (p.111), no obstante, el autor se cuestiona esta declaración de intenciones y dedica un apartado a contextualizar en mayor medida este asunto, adentrándose en cuestiones legislativas y la realidad social y haciendo hincapié en lo que se puede ratificar como un cambio real en el país y lo que no. 
Entre la prensa escrita del país destacan tres diarios: El Universal, El Nacional y Últimas noticias; los tres de carácter privado y neoliberal. Estos han sido los que han conformado el corpus del análisis de la prensa venezolana y donde el autor encuentra, principalmente, la criminalización de las personas trans, representándolas, además, como abyectas y perturbadas. Se alude también a otros aspectos como la violencia o la participación de las personas trans en concursos de belleza.

De nuevo, el autor encuentra en la prensa una representación que tiende a ensuciar la imagen de las personas trans, a faltar al respeto de las misma y deslegitimizar su identidad. No obstante, "como sucede en el caso colombiano, es en las producciones cinematográficas donde se encuentran formas de representación otras" (p.138). En el cuarto capítulo, García León se centra en la película Pelo malo (2013) de la cineasta Mariana Rondón, para ello, realiza una interesante introducción en la que se alude a la infancia trans, un grupo etario cuya subversión de lo identitario ha sido escasamente representada en la industria cinematográfica. También se hace un breve recorrido de otras representaciones del cine trans y LGTBIQ+ venezolano. En su análisis de Pelo malo el autor comparte y analiza la crítica política que se halla en la obra, siendo un tema recurrente tanto de forma explícita como implícita. También se mencionan otras cuestiones relativas a la identidad, no solo no de género.

No se puede sino concluir este libro abriendo camino hacia el futuro, recopilando los aspectos más importantes que se han abordado, lo que debe cambiar, lo que falta por estudiar y qué perspectivas y enfoques podrian ser interesantes y convenientes con miras a nuevos estudios.

Es relevante recordar, por último, que en los últimos años ha proliferado la presencia de personajes trans en los medios, especialmente en los contenidos de ficción seriados, así, Pose (Murphy, Falchuck y Canals, 2018-2021), Euphoria (Levinson, 2019-actualidad), Veneno (Calvo y Ambrossi, 2020) o Sense8 (Wachowski, Wachoski y Straczynski, 2015-2018), han contribuido a la afirmación "la representación importa", demostrando que es necesaria la creación de referentes y la visibilización de realidades hasta ahora ocultas en los medios de masas. En este sentido, han surgido a su vez numerosos estudios, análisis e investigaciones al respecto de estas representaciones, lo que da lugar a libros como el que aquí se reseña, que se centra en desentrañar las representaciones de dos países latinoamericanos, Colombia y Venezuela, aportando con su trabajo mayor visibilidad de las identidades trans y sus representaciones varias en ambos países, con una perspectiva decolonial, queer, crítica y sin olvidar los contextos socioculturales, económicos y políticos de ambas. Contribuyendo, además, a la expansión de estos estudios y a la reflexión acerca de las representaciones por parte de espectadores, investigadores y creadores.

\section{Referencias}

Ambrossi, J. y Calvo, J. (productores y creadores) (2020). Veneno [serie de televisión]. Atresmedia Studios, Suma Latina.

Levinson, S. (productor y creador) (2019-actualidad). Euphoria [serie de televisión]. A24, HBO, Little Lamb, The Reasonable Bunch. 
Murphy, R., Falchuck, B., y Canals, S. (productores y creadores). (2018-2021). Pose [serie de televisión]. Color Force, Brad Falchuk Teley-Vision, Ryan Murphy Television, Fox 21, Television Studios, FXP, FX.

Stryker, S. (2017). Historia de lo trans. Las raíces de la revolución de hoy. Continta me tienes. Washowski, L., Washowski, L., y Straczynski, J. M. (creadores y creadores) (2015-2018). Sense8 [serie de televisión]. Anarchos Productions, Georgeville Television, Javelin Productions, Motion Picture Capital, Studio JMS, Unpronounceable Productions. 